\title{
Determination of the Nucleation and Growth Kinetics for Aqueous L-glycine Solutions from the Turbidity Induction Time Data
}

\author{
Lie-Ding Shiau ${ }^{1,2}$ \\ 1 Department of Chemical and Materials Engineering, Chang Gung University, Taoyuan 333, Taiwan; \\ shiau@mail.cgu.edu.tw \\ 2 Department of Urology, Chang Gung Memorial Hospital Linkou, Taoyuan 333, Taiwan
}

Received: 22 September 2018; Accepted: 23 October 2018; Published: 24 October 2018

\begin{abstract}
As the turbidity induction time measurements are influenced by the size distribution of the nuclei at the detection point, these data should provide important information on both nucleation and growth. A model is developed in this work to determine the nucleation and growth kinetics of aqueous L-glycine solutions using the turbidity induction time data for various supersaturations from $293.15 \mathrm{~K}$ to $313.15 \mathrm{~K}$. The photomicroscopic growth experiments of aqueous L-glycine solutions are also conducted to determine the growth kinetics of nuclei under the same conditions for comparison. The results indicate that the interfacial energy obtained from this model is consistent with that obtained based on the traditional method by assuming $t_{i}{ }^{-1} \propto J$. The growth kinetics, including the growth activation energy and the kinetic growth parameter, obtained from this model using the induction time data are close to those obtained from the photomicroscopic growth experiments performed in this work.
\end{abstract}

Keywords: crystallization; nucleation; induction time; interfacial energy

\section{Introduction}

According to classical nucleation theory (CNT), only nuclei greater than a critical nucleus size are thermodynamically stable and can continue to grow to a detectable size [1-3]. The formation of critical nuclei is closely related to the interfacial energy of the crystallized substance, which is usually calculated from the induction time data in the literature [4-10].

The induction time is defined as the elapsed time between the creation of the supersaturation and the appearance of detectable nuclei at a constant temperature. Although the induction time can be detected by visual observation of the crystal's appearance [7,11], turbidity measurements have been commonly adopted in recent years to determine the induction time by detecting the change in the intensity of transmitted light in solution at the onset of nucleation [12-17]. Traditionally, determination of the interfacial energy from the induction time data is often simplified by assuming $t_{i}^{-1} \propto J[1,4-10]$. Thus, it is implicitly assumed that at the detection of the nucleation point, only the number of the nuclei is accounted for regarding the change in the intensity of transmitted light in solution.

The detection of nucleation point based on turbidity measurements should be influenced by both the number and the size of the nuclei [18] as the change in the intensity of transmitted light in solution is proportional to the size distribution of the nuclei instead of the number of the nuclei. To incorporate the effect of the nuclei size distribution on the detection of nucleation, Shiau and coworkers $[18,19]$ have developed a model to examine the turbidity induction time data of aqueous L-glutamic acid solutions using the L-glutamic acid growth kinetics reported by Scholl et al. [20]. It is found that the obtained interfacial energy and growth activation energy of L-glutamic acid [19] are consistent with 
the literature data. L-glycine is the simplest amino acid and is often used as a model compound in the study of solution nucleation [21-25]. The objective of this work is to develop a model to study the nucleation and growth of aqueous L-glycine solutions based on the turbidity induction time data. To validate the obtained L-glycine growth kinetics from this model, the photomicroscopic growth experiments of aqueous L-glycine solutions are also conducted to determine the growth kinetics of nuclei at the same conditions for comparison.

\section{Theory}

The nucleation rate based on CNT [1-3] is expressed as:

$$
J=A_{J} \exp \left(-\frac{16 \pi v^{2} \gamma^{3}}{3 k_{B}{ }^{3} T^{3} \ln ^{2} S}\right)
$$

where $v=\frac{M_{W}}{\rho_{C} N_{A}}$ and $S=\frac{C}{C_{e q}}$. For simplicity, the nucleation event is assumed to correspond to a point at which the total number density of the nuclei has reached a fixed (but unknown) value, $f_{N}[26,27]$. One obtains at the induction time $t_{i}$ using:

$$
f_{N}=J t_{i}
$$

Thus, it is implicitly assumed that the detection of the nucleation point is related to the number of nuclei. Substituting Equation (1) into Equation (2) yields:

$$
\ln \left(\frac{1}{t_{i}}\right)=\ln \left(\frac{A_{J}}{f_{N}}\right)-\frac{16 \pi v^{2} \gamma^{3}}{3 k_{B}{ }^{3} T^{3} \ln ^{2} S}
$$

This is consistent with the common method adopted in the literature to calculate $\gamma$ from induction time data [1,4-10].

The turbidity induction time measurements are based on the change in intensity of transmitted or scattered light along the detector direction, which should be related to the size distribution of the nuclei instead of the number of the nuclei at the detection point $[18,19]$. As nuclei are progressively generated during the induction time period $\left(t=0-t_{i}\right)$, the nuclei born in the earlier stage will grow to a greater size than those born in the later stage at $t_{i}$. To incorporate the effect of crystal growth at the nucleation point, Shiau and $\mathrm{Lu}$ [18] proposed a model to correlate the nucleation and growth with the turbidity induction time data using the predetermined growth kinetics. However, as it is often difficult to experimentally measure the growth kinetics of small nuclei, the application of this model is restricted.

As the turbidity induction time measurements are influenced by the size distribution of the nuclei, these data should provide important information on both nucleation and growth. A model is developed in the following to investigate the nucleation and growth of nuclei based on the turbidity induction time data without the predetermined growth kinetics. In the derivation, a simple empirical power-law growth rate is proposed as:

$$
G=k_{G}(S-1)^{g}
$$

where the value of $g$ mostly falls between 1 and 2. Based on Burton-Cabrera-Frank (BCF) growth theory [28-30], the value of $g$ is found close to 2 for low supersaturations [31]. Mohan and Myerson [32] indicated for aqueous L-glycine solutions at $293.15 \mathrm{~K}$ that Equation (4) with $g=2$ is consistent with the BCF growth kinetics reported by Li and Rodriguez-Hornedo [33].

In the induction time study, nuclei born at any time $t\left(0<t<t_{i}\right)$ can grow from $t$ to $t_{i}$ and their size at time $t_{i}$ is:

$$
L(t)=G\left(t_{i}-t\right)
$$


The corresponding volume of nuclei with size $L$ at time $t_{i}$ is

$$
V(t)=k_{V} L(t)^{3}=k_{V} G^{3}\left(t_{i}-t\right)^{3},
$$

As nuclei are progressively generated from $t=0$ to $t_{i}$, the total volume of all the nuclei per unit solution volume at time $t_{i}$ is given by:

$$
f_{V}=\int_{0}^{t_{i}} J V(t) d t
$$

Substituting Equation (6) into Equation (7) yields:

$$
f_{V}=J k_{V} G^{3} \int_{0}^{t_{i}}\left(t_{i}-t\right)^{3} d t=\frac{J k_{V} G^{3} t_{i}^{4}}{4}
$$

Note that $J$ and $G$ remain unchanged as $S$ is kept at a particular supersaturation during each induction time experiment.

Substituting Equations (1) and (4) into Equation (8) with $g=2$ leads to:

$$
f_{V}=\frac{A_{J} k_{V} k_{G}^{3}(S-1)^{6} t_{i}^{4}}{4} \exp \left(-\frac{16 \pi v^{2} \gamma^{3}}{3 k_{B}{ }^{3} T^{3} \ln ^{2} S}\right)
$$

Rearranging Equation (9) yields:

$$
\ln \left[\frac{4}{k_{V} t_{i}{ }^{4}(S-1)^{6}}\right]=\ln \left(\frac{A_{J} k_{G}{ }^{3}}{f_{V}}\right)-\frac{16 \pi v^{2} \gamma^{3}}{3 k_{B}{ }^{3} T^{3} \ln ^{2} S},
$$

A plot of $\ln \left[\frac{4}{k_{V} t_{i}^{4}(S-1)^{6}}\right]$ versus $\frac{1}{\ln ^{2} S}$ at a given temperature should give a straight line, the slope and intercept of which permit determination of $\gamma$ and $\frac{A_{J} k_{G}{ }^{3}}{f_{V}}$, respectively.

The temperature dependence of $k_{G}$ can be expressed in terms of the Arrhenius equation as:

$$
k_{G}=A_{G} \exp \left(-\frac{E_{G}}{R T}\right),
$$

Once $\frac{A_{J} k_{G}{ }^{3}}{f_{V}}$ is determined at different temperatures, substitution of Equation (11) yields:

$$
\ln \left(\frac{A_{J} k_{G}{ }^{3}}{f_{V}}\right)=\ln \left(\frac{A_{J} A_{G}{ }^{3}}{f_{V}}\right)-\frac{3 E_{G}}{R T},
$$

Thus, a plot of $\ln \left(\frac{A_{J} k_{G}{ }^{3}}{f_{V}}\right)$ versus $\frac{1}{T}$ should give a straight line, the slope and intercept of which permit determination of $E_{G}$ and $\frac{A_{J} A_{G}{ }^{3}}{f_{V}}$, respectively. It should be noted that $A_{J} A_{G}{ }^{3}$ can be determined if $f_{V}$ is known.

\section{Experimental}

\subsection{Induction Time Measurements}

The experimental apparatus of a $250 \mathrm{~mL}$ crystallizer was the same as that used by Shiau and Lu [18]. Deionized water and L-glycine ( $>99 \%$, Alfa Aesar, Haverhill, MA, USA) were used to prepare the supersaturated solution. In each experiment, a $200 \mathrm{~mL}$ aqueous L-glycine solution with the desired supersaturation was loaded into the crystallizer. The solution was stirred with a magnetic stirrer at a constant stirring rate of $350 \mathrm{rpm}$. A turbidity probe with a Near-Infrared source (Crystal Eyes 
manufactured by HEL limited, Hertford, UK) was used to detect the nucleation event during the induction time study. The solution is held at $3 \mathrm{~K}$ above the saturated temperature for 5-10 min to ensure a complete dissolution at the beginning of the experiment, which was also confirmed using the turbidity measurement. As the cooling rate to reach a particular supersaturation influences the nucleation induction time [34], the solution was rapidly cooled at $25^{\circ} \mathrm{C} / \mathrm{min}$ to the desired constant temperature. Thus, the lag time was usually less than $60 \mathrm{~s}$, which was much smaller than the measured induction times listed in Table 1. Figure 1 shows the variation of measured turbidity with time for $S=1.15$ and a temperature of $293.15 \mathrm{~K}$. The percentage threshold for the turbidity data was defined as the change in turbidity to determine whether a nucleation event had occurred [35]. A setting of $20 \%$ for the threshold was employed for all the turbidity induction time data in this work.

Table 1. The average induction times and the corresponding standard deviations (SD) for L-Glycine.

\begin{tabular}{ccc}
\hline $\boldsymbol{T ( K )}$ & $\boldsymbol{S ( - )}$ & $\boldsymbol{t}_{\boldsymbol{i}}(\boldsymbol{S D})(\mathrm{s})$ \\
\hline & 1.10 & $2120(471)$ \\
293.15 & 1.12 & $1090(242)$ \\
& 1.13 & $936(253)$ \\
& 1.16 & $563(157)$ \\
\hline & 1.07 & $2672(588)$ \\
303.15 & 1.08 & $1390(276)$ \\
& 1.10 & $831(247)$ \\
& 1.12 & $442(198)$ \\
\hline & 1.06 & $2327(534)$ \\
313.15 & 1.07 & $953(273)$ \\
& 1.08 & $737(201)$ \\
& 1.10 & $429(175)$ \\
\hline
\end{tabular}

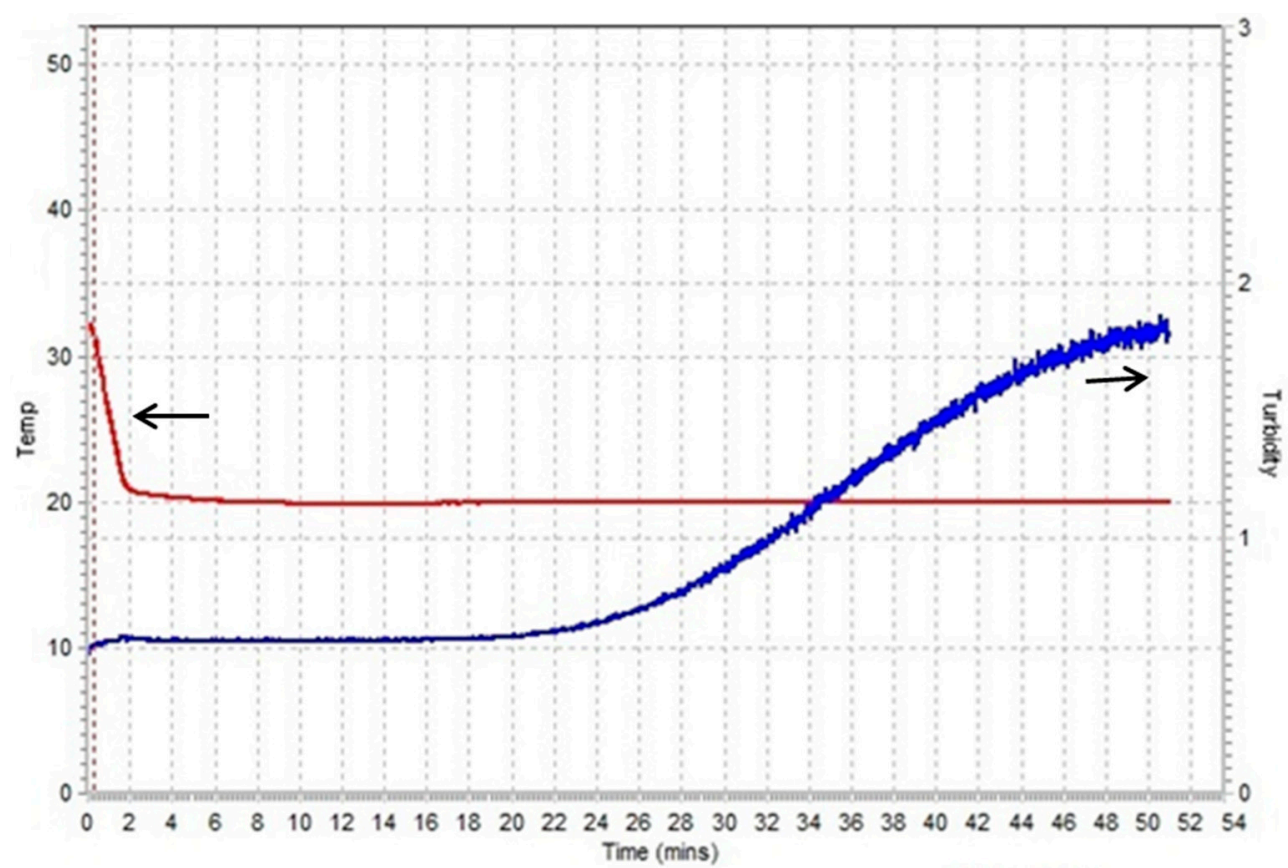

Figure 1. The variation of measured turbidity with time for $S=1.15$ and $293.15 \mathrm{~K}$.

\subsection{Growth Rate Measurements}

The photomicroscopic experiments shown are performed to investigate the growth rates of L-glycine in water. This growth cell shown in Figure 2 [36] has a solution chamber of $20 \mathrm{~mL}$ in the upper part and a chamber for temperature-controlled water in the lower part. The growth rates of 
aqueous L-glycine solutions for various supersaturations from $293.15 \mathrm{~K}$ to $313.15 \mathrm{~K}$ were studied isothermally in the upper stagnant solution.

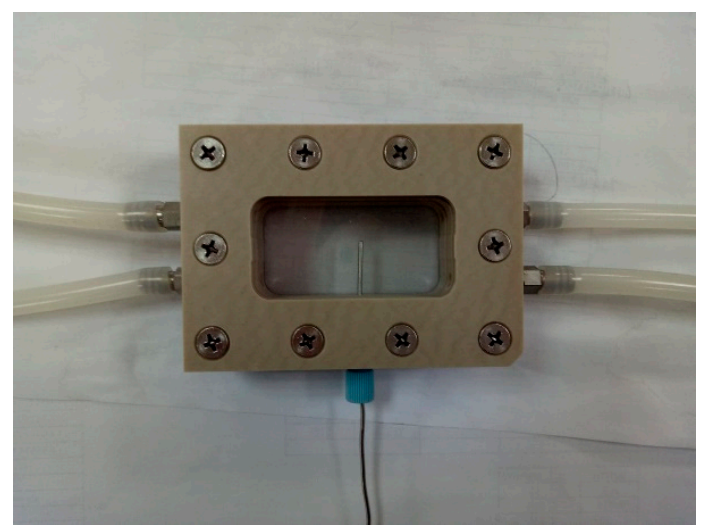

Top view

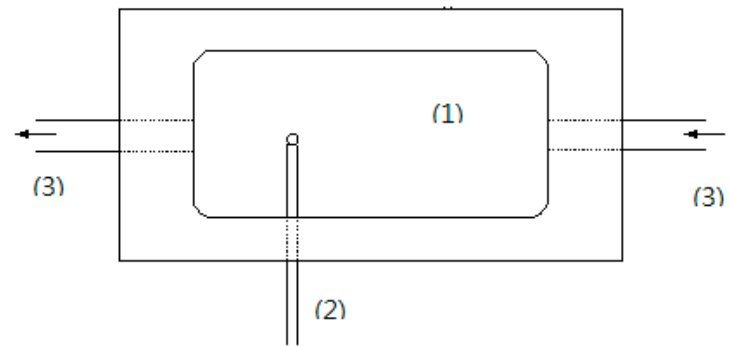

Top view

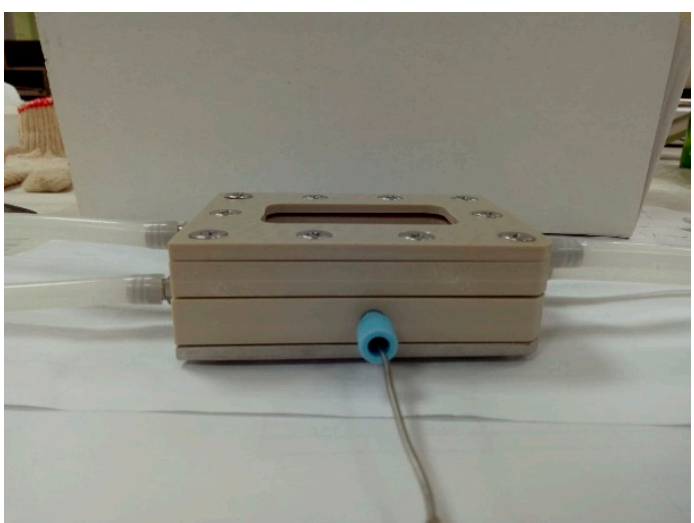

Side view

(a)

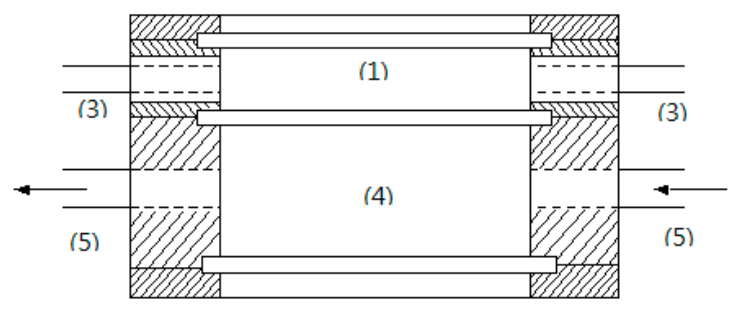

Side view

(b)

Figure 2. The photomicroscopic growth apparatus (a) the real picture of growth cell; (b) schematic diagram of growth cell with the features: (1) solution chamber; (2) thermistor; (3) solution inlet and outlet; (4) constant-temperature water chamber; (5) water inlet and outlet.

The growth of crystals was monitored photographically through a microscope and analyzed using an image analyzer (Imaging Software, NIS-Elements, Nikon, Japan) to determine the area of each crystal. For simplicity, the characteristic size of the small crystal is taken as the equivalent circular diameter, i.e., $A=\pi L^{2} / 4$, leading to $L=\sqrt{4 A / \pi}$. The sizes were then plotted against time for each crystal with the slope equal to the growth rate. In each run, 8-10 crystals were analyzed to calculate the mean growth rate among these crystals under each condition. Figure 3 shows the photograph of the needle-like $\alpha$-form crystals in solution taken in an experimental run for $S=1.12$ at $T=303.15 \mathrm{~K}$. It was found for various supersaturations from $293.15 \mathrm{~K}$ to $313.15 \mathrm{~K}$ that the needle-like $\alpha$-form crystals were nucleated in the photomicroscopic experiments. 


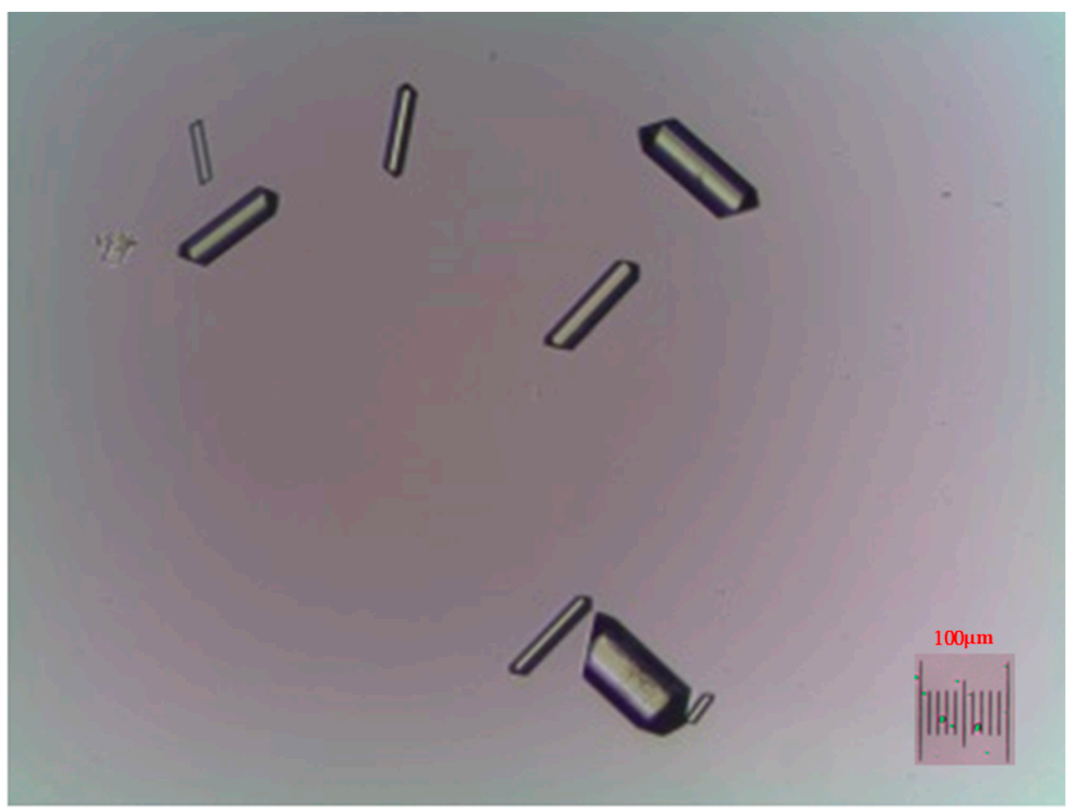

Figure 3. The photograph of the needle-like $\alpha$-form L-glycine crystals in solution taken in the photomicroscopic experiment at $S=1.12$ and $303.15 \mathrm{~K}$.

\section{Results and Discussion}

The induction time data for aqueous L-glycine solutions were measured for various supersaturations from $293.15 \mathrm{~K}$ to $313.15 \mathrm{~K}$. Each run was carried out at least three times to determine the average induction time under each condition. The average induction times and the corresponding standard deviations (SD) are listed in Table 1. The equilibrium concentration of the $\alpha$-form L-glycine in water was given by $C_{e q}(T)=5.4397 \times 10^{-3} T^{2}-3.2022 \times 10^{-1} T-188.2\left(C_{e q}\right.$ in $\mathrm{kg} / \mathrm{m}^{3}$, and $T$ in K) [37]. Note that $M_{W}=0.075 \mathrm{~kg} / \mathrm{mol}, \rho_{C}=1607 \mathrm{~kg} / \mathrm{m}^{3}$, and $v=7.757 \times 10^{-29} \mathrm{~m}^{3}$ for L-glycine.

Although L-glycine can be crystallized in different polymorphs, the $\alpha$-form is usually achieved from nucleation of pure aqueous solutions [21-25]. To validate the polymorphm of the L-glycine crystals, the final dried crystals at the end of the induction time experiments were analyzed using both optical microscopy and Raman spectroscopy (P/N LSI-DP2-785 Dimension-P2 System, $785 \mathrm{~nm}$, manufactured by Lambda Solutions, INC., Seattle, WA, USA). The results all indicated that the needle-like $\alpha$-form crystals were obtained from aqueous L-glycine solutions for various supersaturations from $293.15 \mathrm{~K}$ to $313.15 \mathrm{~K}$. Figure 4 shows the Raman spectra of pure $\alpha$-form crystals and product crystals obtained at various supersaturations. As compared with the Raman spectra of pure $\alpha$-form crystals reported by Murli et al. [38], it was confirmed that $\alpha$-form crystals were produced for various supersaturations at $303.15 \mathrm{~K}$. The section of the Raman spectra of $\alpha-, \beta-$, and $\gamma$-glycine used for characterization are also depicted by Bouchard et al. [39].

Figure 5 shows the measured induction time data from $293.15 \mathrm{~K}$ to $313.15 \mathrm{~K}$ fitted to Equation (3) based on $f_{N}$. The fitted results are listed in Table 2, where $\gamma$ was in the range $1.93-2.37 \mathrm{~mJ} / \mathrm{m}^{2}$ and $\frac{A_{J}}{f_{N}}$ was in the range $4.35 \times 10^{-3}-6.42 \times 10^{-3} \mathrm{~s}^{-1}$. Although the exact value of $A_{J}$ could only be determined with a known value of $f_{N}, \gamma$ was not influenced by the chosen value of $f_{N}$.

Table 2. The fitted results of the induction time data to Equation (3) based on $f_{N}$.

\begin{tabular}{cccc}
\hline $\boldsymbol{T}(\mathbf{K})$ & $\gamma\left(\mathbf{m J} / \mathbf{m}^{2}\right)$ & $\frac{A_{J}}{f_{N}}\left(\mathbf{s}^{-\mathbf{1}}\right)$ & $A_{J}\left(\mathbf{m}^{-\mathbf{3}} \mathbf{s}^{-\mathbf{1}}\right)$ \\
\hline 293.15 & 2.37 & $4.35 \times 10^{-3}$ & $3.32 \times 10^{9}$ \\
303.15 & 2.07 & $5.29 \times 10^{-3}$ & $4.04 \times 10^{9}$ \\
313.15 & 1.93 & $6.42 \times 10^{-3}$ & $4.91 \times 10^{9}$ \\
\hline
\end{tabular}




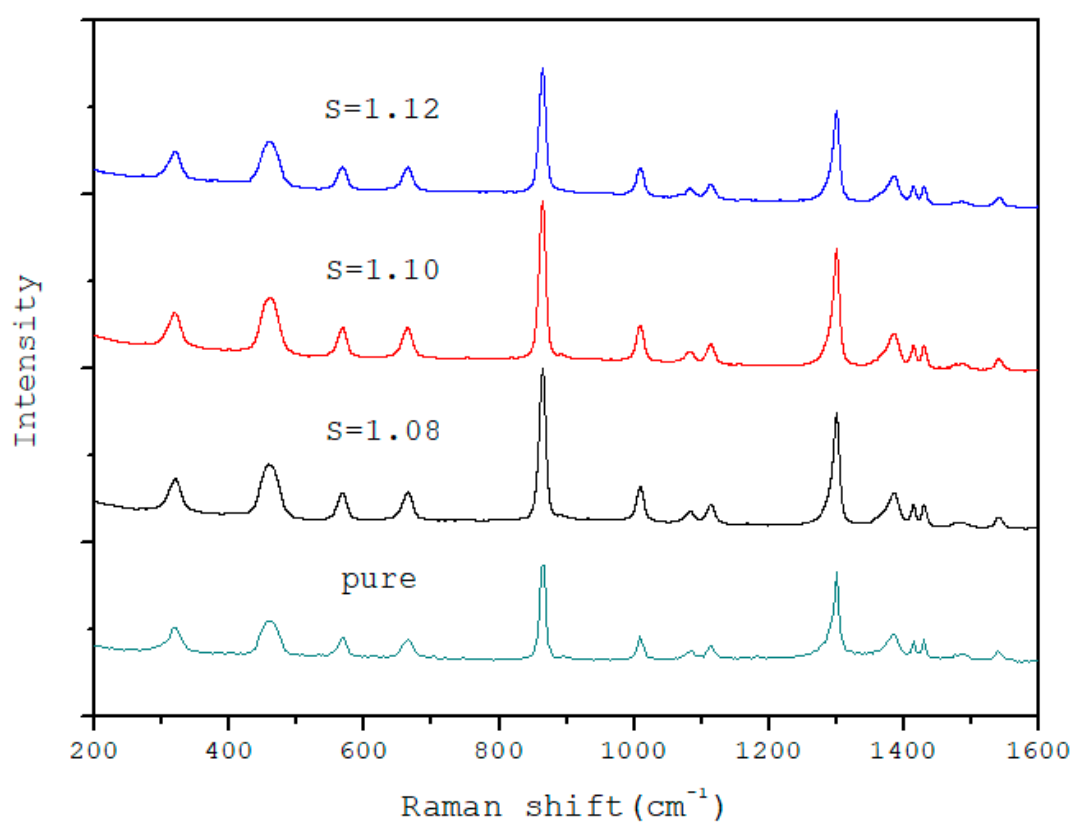

Figure 4. The Raman spectra of pure $\alpha$-form crystals and product crystals obtained in the induction time experiments for various supersaturations at $303.15 \mathrm{~K}$.

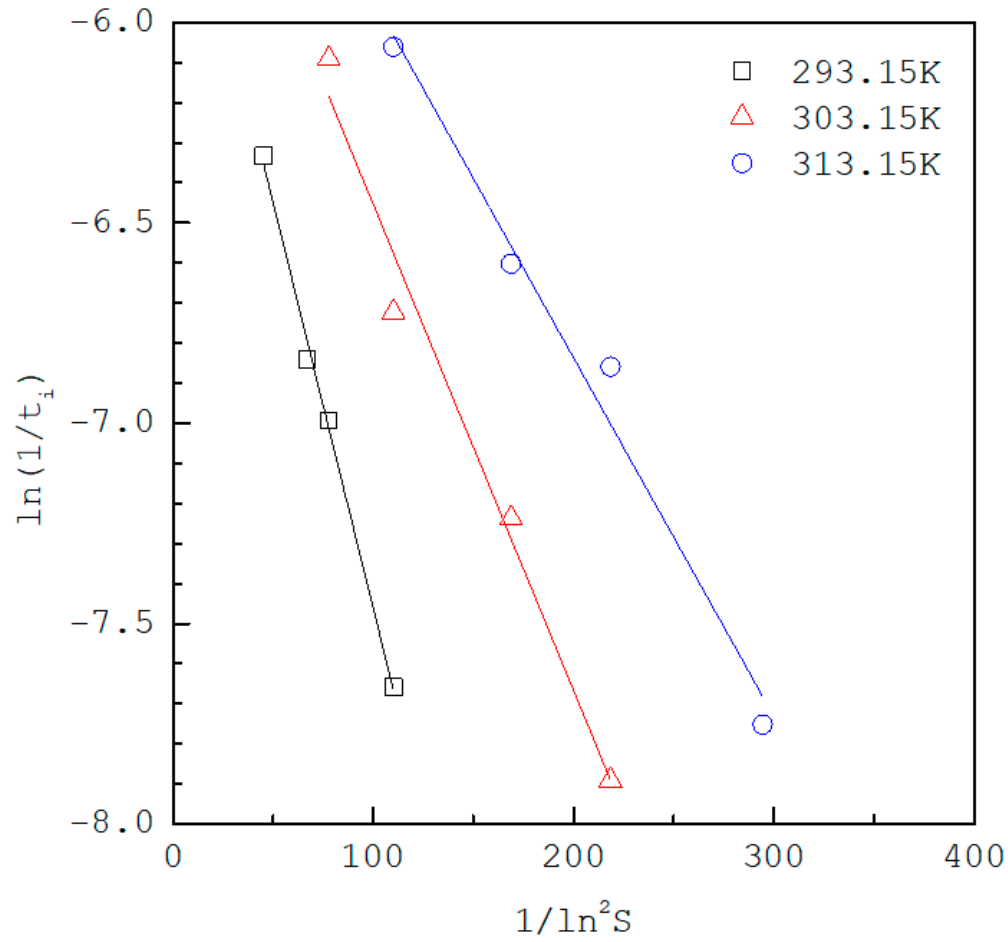

Figure 5. The induction time data of L-glycine at $293.15-313.15 \mathrm{~K}$ fitted to Equation (3) based on $f_{N}$.

As the induction time data are measured by the intensity change of the transmitted light, Figure 6 shows the measured induction time data from $293.15 \mathrm{~K}$ to $313.15 \mathrm{~K}$ fitted to Equation (10) based on $f_{V}$. Note that $g$ was assumed to be 2 due to low supersaturations $(S=1.4-2.4)$ in the induction time experiments. The fitted results are listed in Table 3, where $\gamma$ was in the range $2.49-2.93 \mathrm{~mJ} / \mathrm{m}^{2}$ and $\frac{A_{J} k_{G}{ }^{3}}{f_{V}}$ was in the range $2.78 \times 10^{-5}-2.58 \times 10^{-3} \mathrm{~s}^{-4}$. It should be noted that $\gamma$ was not influenced by the chosen value of $f_{V}$. 


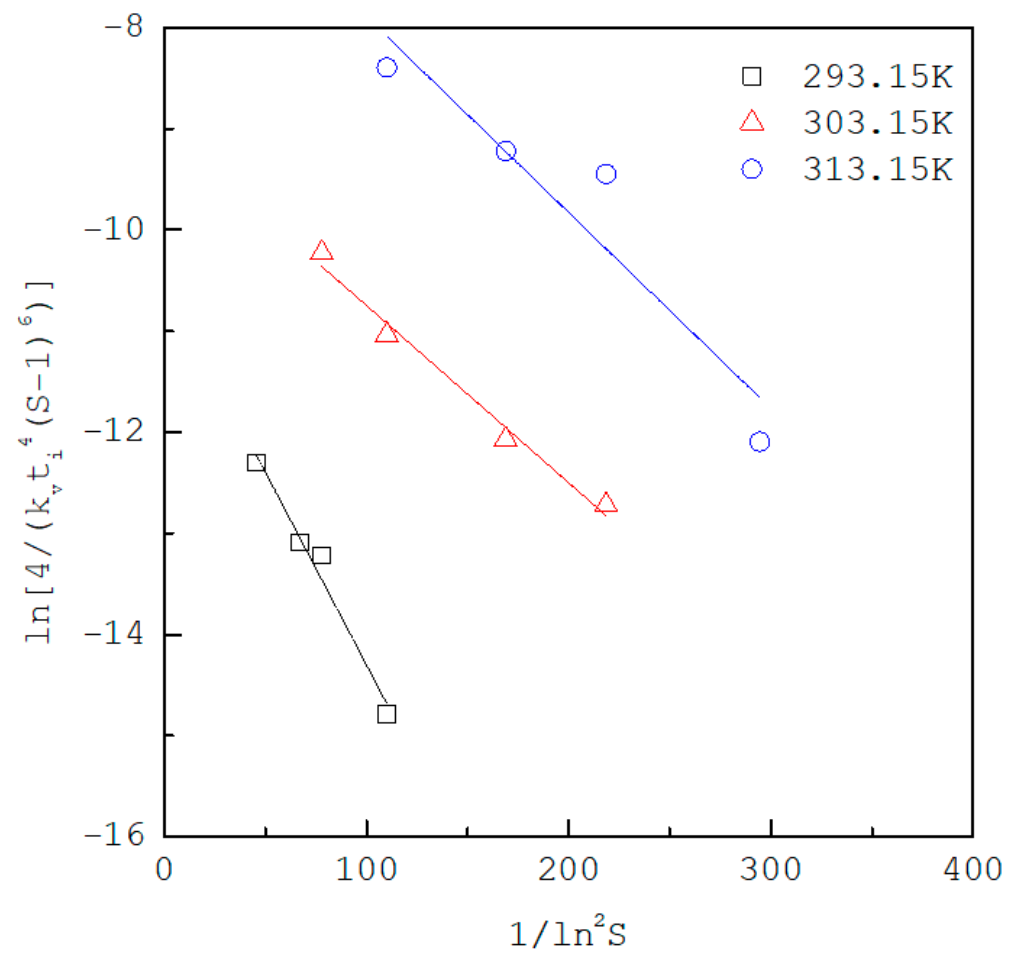

Figure 6. The induction time data of L-glycine at $293.15-313.15 \mathrm{~K}$ fitted to Equation (10) based on $f_{V}$.

Table 3. The fitted results of the induction time data to Equation (10) based on $f_{V}$.

\begin{tabular}{ccc}
\hline $\boldsymbol{T}(\mathbf{K})$ & $\gamma\left(\mathbf{m J} / \mathbf{m}^{2}\right)$ & $\frac{A_{J} k_{G}{ }^{3}}{f_{V}}\left(\mathbf{s}^{-4}\right)$ \\
\hline 293.15 & 2.93 & $2.78 \times 10^{-5}$ \\
303.15 & 2.66 & $4.15 \times 10^{-4}$ \\
313.15 & 2.49 & $2.58 \times 10^{-3}$ \\
\hline
\end{tabular}

The turbidity induction time measurements in the current experiments were based on the intensity change of the transmitted light, which is related to $f_{V}$. Thus, compared to $\gamma$ based on $f_{N}, \gamma$ based on $f_{V}$ should more accurately represent the actual interfacial energy of L-glycine. Shiau [40] reported $\gamma=1.35-2.02 \mathrm{~mJ} / \mathrm{m}^{2}$ for aqueous $\alpha$-form L-glycine solutions using the turbidity metastable zone width measurements at the saturation temperature between $308.15 \mathrm{~K}$ and $328.15 \mathrm{~K}$. Using the visual observation of the induction time data, Devi and Srinivasan [25] reported $\gamma=5 \mathrm{~mJ} / \mathrm{m}^{2}$ for aqueous $\alpha$-form L-glycine solutions at $303.15 \mathrm{~K}$.

Figure 7 shows the plot of $\frac{A_{J} k_{G}{ }^{3}}{f_{V}}$ versus $\frac{1}{T}$ fitted to Equation (12). The fitted results are listed in Table 4, which indicates $E_{G}=58 \mathrm{~kJ} / \mathrm{mol}$ and $\frac{A_{J} A_{G}{ }^{3}}{f_{V}}=2.30 \times 10^{26} \mathrm{~s}^{-4}$. Although the exact value of $A_{J} A_{G}{ }^{3}$ could only be determined with a known value of $f_{V}, E_{G}$ was not influenced by the chosen value of $f_{V}$. Because activation energy is usually $10-20 \mathrm{~kJ} / \mathrm{mol}$ for diffusion and $40-60 \mathrm{~kJ} / \mathrm{mol}$ for surface integration [1], $E_{G}=58 \mathrm{~kJ} / \mathrm{mol}$ obtained for the growth of L-glycine in the induction time experiments should be integration controlled.

Table 4. The fitted results of $E_{G}$ and $A_{G}$ using Equation (12).

\begin{tabular}{|c|c|c|c|c|c|}
\hline \multirow{2}{*}{$E_{G}\left(\frac{\mathrm{kJ}}{\mathrm{mol}}\right)$} & \multirow{2}{*}{$\frac{A_{I} A_{G}{ }^{3}}{f_{V}}\left(\mathbf{s}^{-4}\right)$} & \multirow{2}{*}{$A_{J} A_{G}{ }^{3}\left(\mathrm{~s}^{-4}\right)$} & \multicolumn{3}{|c|}{$A_{G}(\mathrm{~m} / \mathrm{s})$} \\
\hline & & & $293.15 \mathrm{~K}$ & $303.15 \mathrm{~K}$ & $313.15 \mathrm{~K}$ \\
\hline 58 & $2.30 \times 10^{26}$ & $9.18 \times 10^{22}$ & $3.02 \times 10^{4}$ & $2.83 \times 10^{4}$ & $2.66 \times 10^{4}$ \\
\hline
\end{tabular}




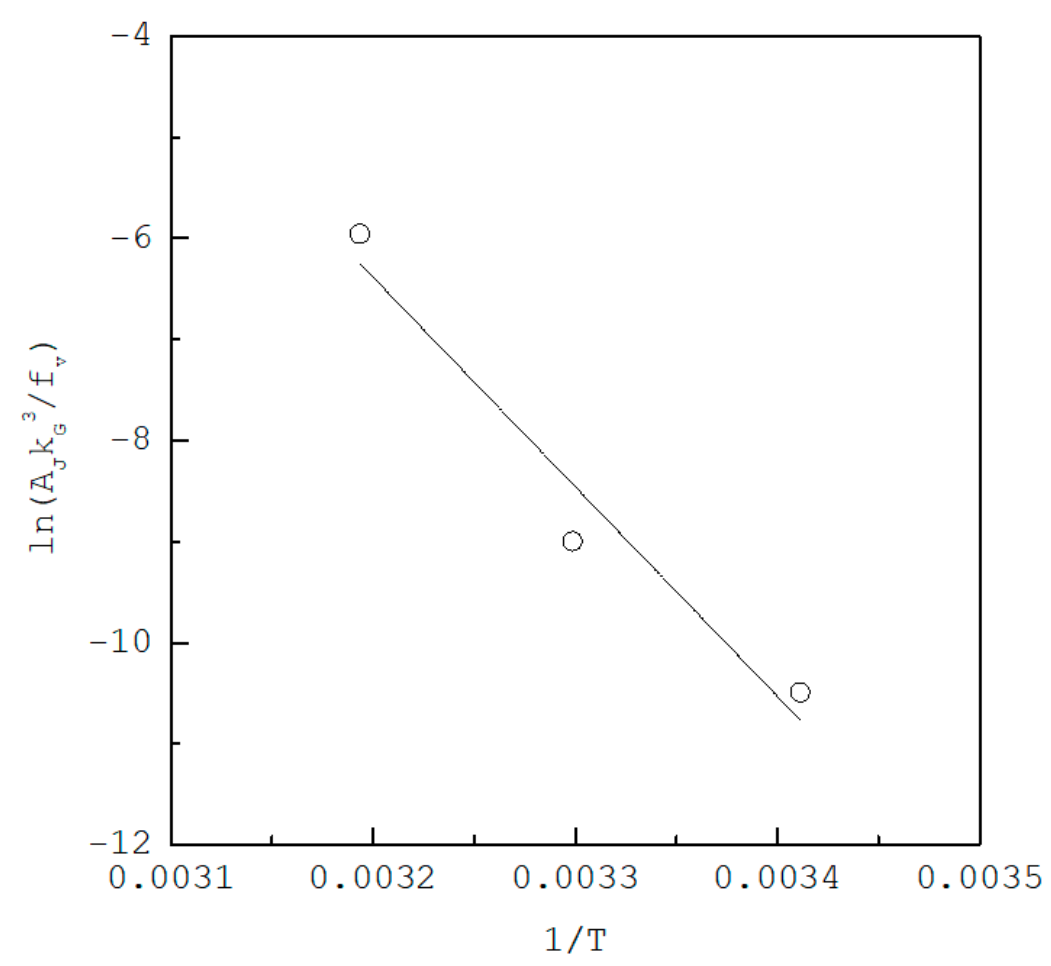

Figure 7. The plot of $\frac{A_{J} k_{G}{ }^{3}}{f_{V}}$ versus $\frac{1}{T}$ fitted to Equation (12).

Based on the study of 28 inorganic systems, Mersmann and Bartosch [41] estimated $f_{V}=10^{-4}-10^{-3}$ with a detectable size of $10 \mu \mathrm{m}$. In the calculations here, the intermediate value, $f_{V}=4 \times 10^{-4}$, for spherical nuclei with $k_{V}=\frac{\pi}{6}$ was assumed, leading to $f_{N}=7.64 \times 10^{11} \mathrm{~m}^{-3}$. Consequently, as indicated in Table 2, $A_{J}$ was in the range $3.32 \times 10^{9}-4.91 \times 10^{9} \mathrm{~m}^{-3} \cdot \mathrm{s}^{-1}$ based on $f_{N}=7.64 \times 10^{11} \mathrm{~m}^{-3}$. Table 4 indicates $A_{J} A_{G}{ }^{3}=9.18 \times 10^{22} \mathrm{~s}^{-4}$ based on $f_{V}=4 \times 10^{-4}$. For simplicity, if $A_{J}$ obtained based on $f_{N}$ was adopted to find $A_{G}$, one obtains $A_{G}=2.66 \times 10^{4}-3.02 \times 10^{4} \mathrm{~m} / \mathrm{s}$.

The average growth rates and the corresponding standard deviations (SD) obtained from the photomicroscopic growth experiments are listed in Table 5. Figure 8 displays the growth rate data for various supersaturation from $303.15 \mathrm{~K}$ to $323.15 \mathrm{~K}$. The growth rate obtained here is consistent with that reported by Han et al. [23] for aqueous $\alpha$-form L-glycine solutions at $S=1.35$ and $T=303.15 \mathrm{~K}$. Substituting Equation (11) into Equation (4) for $g=2$ yields:

$$
G=A_{G} \exp \left(-\frac{E_{G}}{R T}\right)(S-1)^{2},
$$

Rearranging Equation (13) leads to:

$$
\ln \left[\frac{G}{(S-1)^{2}}\right]=\ln A_{G}-\frac{E_{G}}{R T}
$$

As shown in Figure 9, a plot of $\ln \left[\frac{G}{(S-1)^{2}}\right]$ versus $\frac{1}{T}$ should give a straight line, leading to $E_{G}=57$ $\mathrm{kJ} / \mathrm{mol}$ and $A_{G}=6.05 \times 10^{4} \mathrm{~m} / \mathrm{s}$. 
Table 5. The average growth rates and the corresponding standard deviations (SD) for L-Glycine.

\begin{tabular}{ccc}
\hline $\boldsymbol{T}(\mathbf{K})$ & $\boldsymbol{S ( - )}$ & $\boldsymbol{G}(\mathbf{S D})\left(\times \mathbf{1 0}^{-\mathbf{7}}\right)(\mathbf{m} / \mathbf{s})$ \\
\hline & 1.08 & $0.42(0.17)$ \\
303.15 & 1.10 & $0.67(0.29)$ \\
& 1.12 & $1.09(0.36)$ \\
& 1.14 & $1.35(0.55)$ \\
\hline \multirow{3}{*}{313.15} & 1.08 & $1.03(0.42)$ \\
& 1.10 & $1.67(0.85)$ \\
& 1.12 & $1.87(0.64)$ \\
323.15 & 1.14 & $3.21(1.37)$ \\
& 1.08 & $2.13(0.73)$ \\
& 1.10 & $2.55(0.82)$ \\
& 1.14 & $3.88(1.03)$ \\
\end{tabular}

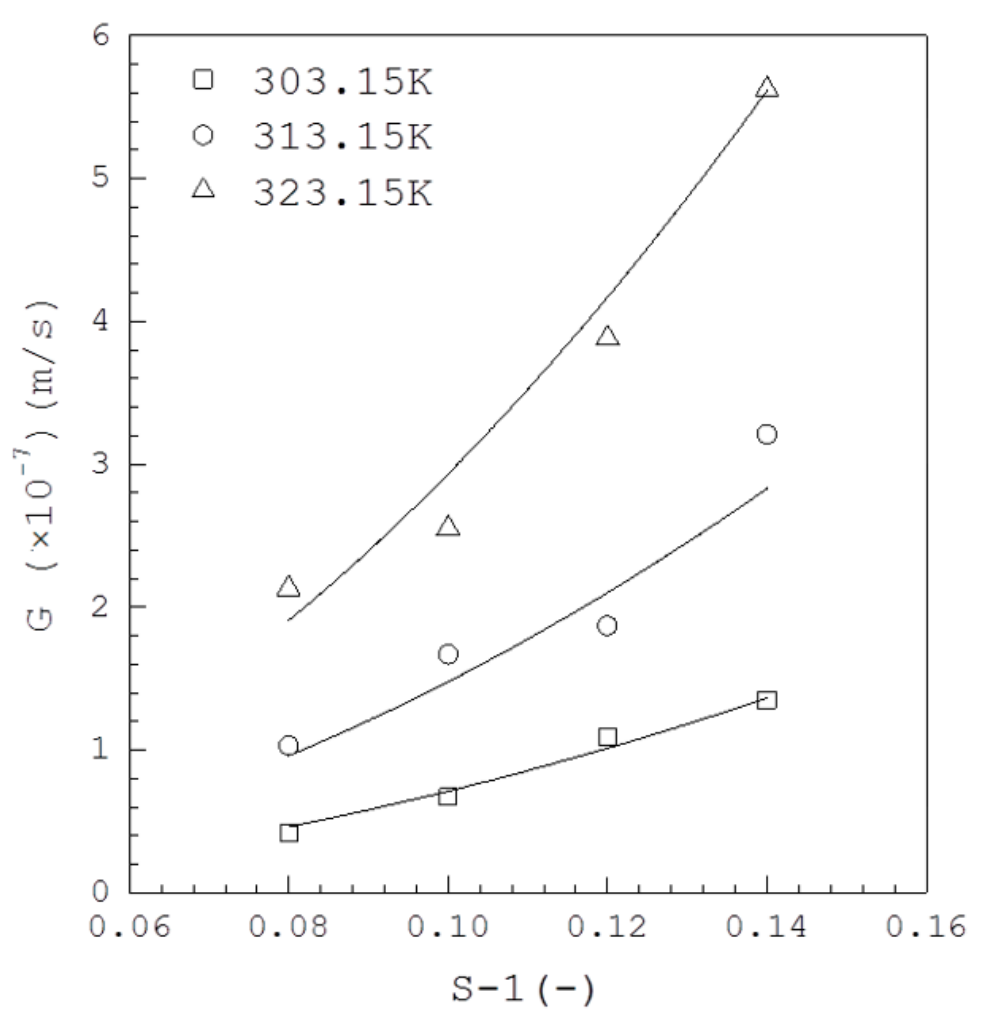

Figure 8. The growth rate data of L-glycine for various supersaturations at $303.15-323.15 \mathrm{~K}$. The lines represent the fitted values to Equation (13) using $g=2, E_{G}=57 \mathrm{~kJ} / \mathrm{mol}$ and $A_{G}=6.05 \times 10^{4} \mathrm{~m} / \mathrm{s}$.

Figure 8 shows the growth rate data fitted well to Equation (14) using $g=2$ and the fitted values of $E_{G}$ and $A_{G}$. Thus, it was reasonable to adopt the power-law growth rate of Equation (4) with $g=2$ in derivation of Equation (10). It should be noted that the turbidity induction time data were measured for nuclei of near-zero size $\left(<10 \mu \mathrm{m}\right.$, as assumed here for $f_{V}=4 \times 10^{-4}$ and $\left.f_{N}=7.64 \times 10^{11} \mathrm{~m}^{-3}\right)$ in the $200 \mathrm{~mL}$ stirred solution while the photomicroscopic growth data were measured for nuclei of size $L=50-100 \mu \mathrm{m}$ in the $20 \mathrm{~mL}$ stagnant solution. Nevertheless, $E_{G}$ obtained from the growth rate data was close to that obtained from the induction time data while $A_{G}$ obtained from the growth rate data was still quite consistent with that obtained from the induction time data. 


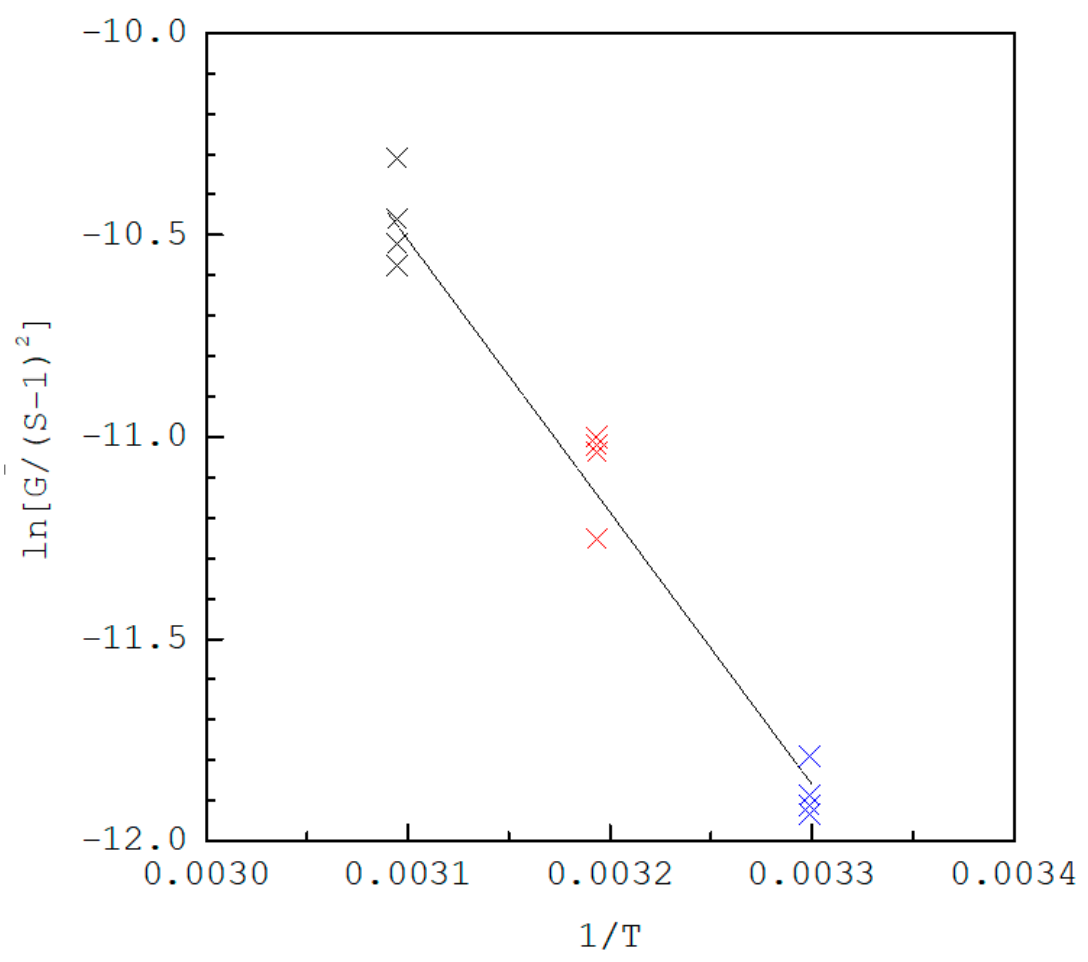

Figure 9. The growth rate data of L-glycine for various supersaturations at 303.15-323.15 K fitted to Equation (14).

\section{Conclusions}

In practical applications, the turbidity induction time measurements should be more related to the volume fraction of the nuclei than to the number density of the nuclei. A model is developed in this work to determine the interfacial energy and growth activation energy of aqueous L-glycine solutions from the turbidity induction time data without the knowledge of the actual growth kinetics. The results reveal that the interfacial energy of L-glycine obtained in this work is close to that calculated based on the traditional method by assuming $t_{i}{ }^{-1} \propto J$, and the growth activation energy of L-glycine obtained from the induction time data was close to that obtained from the photomicroscopic growth experiments. The kinetic growth parameter of L-glycine obtained from the photomicroscopic growth experiments was consistent with that obtained from the induction time data. Thus, the proposed model in this work provides an efficient method to determine the nucleation and growth kinetics of nuclei using the induction time data.

Funding: The author would like to thank Chang Gung Memorial Hospital (CMRPD2G0241) and Ministry of Science and Technology of Taiwan (MOST106-2221-E-182-053) for financial support of this research.

Acknowledgments: The author would like to thank Chang Gung Memorial Hospital (CMRPD2G0241) and Ministry of Science and Technology of Taiwan (MOST106-2221-E-182-053) for financial support of this research. The author also expresses his gratitude to Szu-Yu Lin and Yi-Ting Chen for their experimental work.

Conflicts of Interest: The author declares no conflict of interest. The funders had no role in the design of the study; in the collection, analyses, or interpretation of data; in the writing of the manuscript, and in the decision to publish the results. 


\section{Notation}

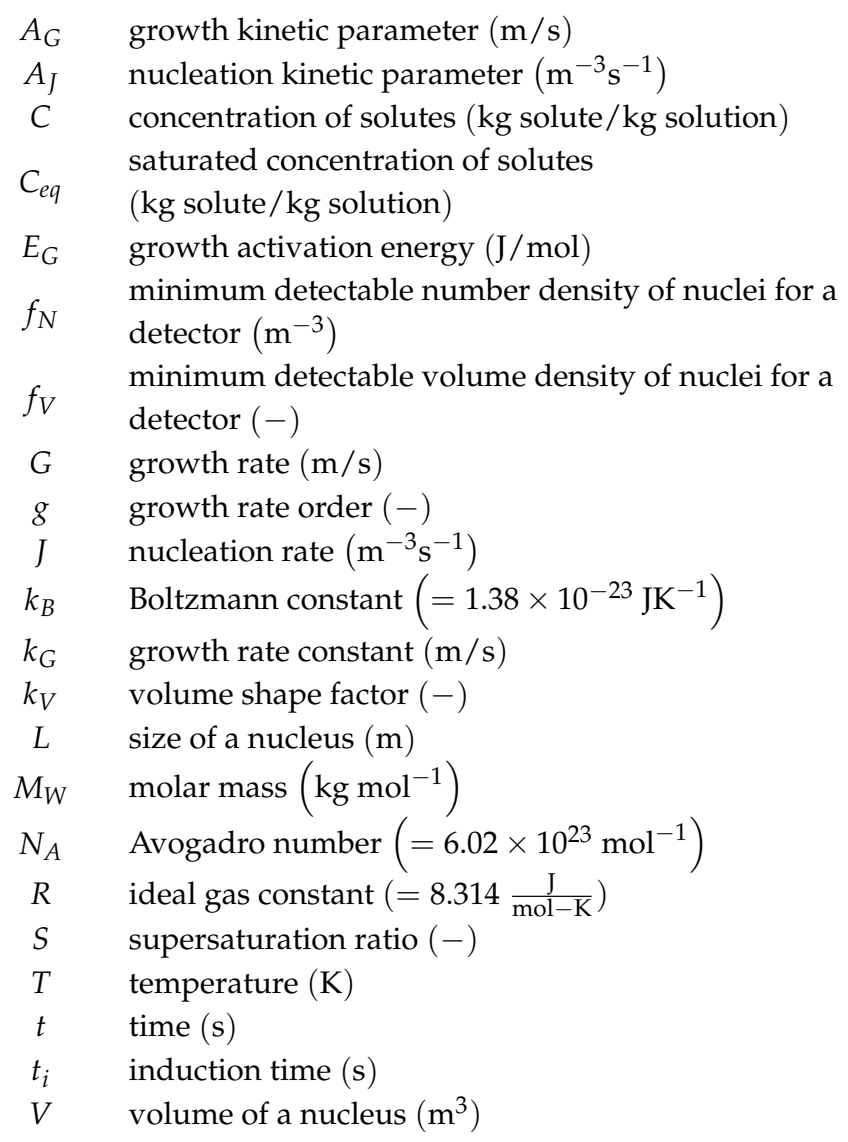

\section{Greek letters}

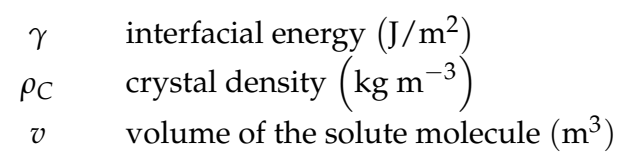

\section{References}

1. Mullin, J.W. Crystallization; Butterworth-Heinemann: Oxford, UK, 1993.

2. Kashchiev, D. Nucleation: Basic Theory with Applications; Butterworth-Heinemann: Oxford, UK, 2000.

3. Kashchiev, D.; van Rosmalen, G.M. Review: Nucleation in solutions revisited. Cryst. Res. Technol. 2003, 38, 555-574. [CrossRef]

4. Omar, W.; Mohnicke, M.; Ulrich, J. Determination of the solid liquid interfacial energy and thereby the critical nucleus size of paracetamol in different solvents. Cryst. Res. Technol. 2006, 41, 337-343. [CrossRef]

5. Lindenberg, C.; Mazzotti, M. Effect of temperature on the nucleation kinetics of $\alpha$ L-glutamic acid. J. Cryst. Growth 2009, 311, 1178-1184. [CrossRef]

6. Du, W.; Yin, Q.; Bao, Y.; Xie, C.; Hou, B.; Hao, H.; Chen, W.; Wang, J.; Gong, J. Concomitant polymorphism of prasugrel hydrochloride in reactive crystallization. Ind. Eng. Chem. Res. 2013, 52, 16182-16189. [CrossRef]

7. Yang, H.; Rasmuson, A.C. Nucleation of butyl paraben in different solvents. Cryst. Growth Des. 2013, 13, 4226-4238. [CrossRef]

8. You, S.; Zhang, Y.; Zhang, Y. Nucleation of ammonium sulfate dodecahydrate from unseeded aqueous solution. J. Cryst. Growth 2015, 411, 24-29. [CrossRef]

9. Yang, H. Relation between metastable zone width and induction time of butyl paraben in ethanol. CrystEngComm 2015, 17, 577-586. [CrossRef]

10. Lee, J.; Yang, S. Antisolvent sonocrystallization of sodium chloride and the evaluation of the ultrasound energy using modified classical nucleation theory. Crystals 2018, 8, 320. [CrossRef] 
11. Vancleef, A.; Seurs, S.; Jordens, J.; Van Gerven, T.; Thomassen, L.C.J.; Braeken, L. Reducing the induction time using ultrasound and high-shear mixing in a continuous crystallization process. Crystals 2018, 8, 326. [CrossRef]

12. Kuldipkumar, A.; Kwon, G.S.; Zhang, G.G.Z. Determining the growth mechanism of tolazamide by induction time measurement. Cryst. Growth Des. 2007, 7, 234-242. [CrossRef]

13. Kadam, S.S.; Kramer, H.J.M.; ter Horst, J.H. Combination of a single primary nucleation event and secondary nucleation in crystallization processes. Cryst. Growth Des. 2011, 11, 1271-1277. [CrossRef]

14. Jiang, S.; ter Horst, J.H. Crystal nucleation rates from probability distributions of induction times. Cryst. Growth Des. 2011, 11, 256-261. [CrossRef]

15. Mitchell, N.A.; Frawley, P.J.; O'Ciardha, C.T. Nucleation kinetics of paracetamol-ethanol solutions from induction time experiments using Lasentec FBRM. J. Cryst. Growth 2011, 321, 91-99. [CrossRef]

16. Prisciandaro, M.; Olivieri, E.; Lancia, A.; Musmarra, D. PBTC as an antiscalant for gypsum precipitation: Interfacial tension and activation energy estimation. Ind. Eng. Chem. Res. 2012, 51, 12844-12851. [CrossRef]

17. Camacho Corzo, D.M.; Borissova, A.; Hammond, R.B.; Kashchiev, D.; Roberts, K.J.; Lewtas, K.; More, I. Nucleation mechanism and kinetics from the analysis of polythermal crystallization data: Methyl stearate from kerosene solutions. CrystEngComm 2014, 16, 974-991. [CrossRef]

18. Shiau, L.D.; Lu, T.S. A model for determination of the interfacial energy from the induction time or metastable zone width data based on turbidity measurements. CrystEngComm 2014, 16, 9743-9752. [CrossRef]

19. Shiau, L.D.; Wang, H.P. Simultaneous determination of interfacial energy and growth activation energy from induction time measurements. J. Cryst. Growth 2016, 442, 47-51. [CrossRef]

20. Scholl, J.; Lindenberg, C.; Vicum, L.; Brozio, J.; Mazzotti, M. Precipitation of $\alpha$ L-glutamic acid: Determination of growth kinetics. Faraday Discuss. 2007, 136, 247-264. [CrossRef] [PubMed]

21. Towler, C.S.; Davey, R.J.; Lancaster, R.W.; Price, C.J. Impact of molecular speciation on crystal nucleation in polymorphic systems: The conundrum of $\gamma$ glycine and molecular 'self poisoning'. J. Am. Chem. Soc. 2004, 126, 13347-13353. [CrossRef] [PubMed]

22. Sun, X.; Garetz, B.A.; Myerson, A.S. Supersaturation and polarization dependence of polymorph control in the nonphotochemical laser-induced nucleation(NPLIN) of aqueous glycine solutions. Cryst. Growth Des. 2006, 6, 684-689. [CrossRef]

23. Han, G.; Chow, P.S.; Tan, R.B.H. Direct comparison of $\alpha$ - and $\gamma$-glycine growth rates in acidic and basic solutions: New insights into glycine polymorphism. Cryst. Growth Des. 2012, 12, 2213-2220. [CrossRef]

24. Yani, Y.; Chow, P.S.; Tan, R.B.H. Glycine Open Dimers in Solution: New Insights into $\alpha$-Glycine Nucleation and Growth. Cryst. Growth Des. 2012, 12, 4771-4778. [CrossRef]

25. Devi, K.R.; Srinivasan, K. A novel approach to understand the nucleation kinetics of $\alpha$ and $\gamma$ polymorphs of glycine from aqueous solution in the presence of a selective additive through charge compensation mechanism. CrystEngComm 2014, 16, 707-722. [CrossRef]

26. Kubota, N. A new interpretation of metastable zone widths measured for unseeded solutions. J. Cryst. Growth 2008, 310, 629-634. [CrossRef]

27. Kobari, M.; Kubota, N.; Hirasawa, I. Deducing primary nucleation parameters from metastable zone width and induction time data determined with simulation. CrystEngComm 2013, 15, 1199-1209. [CrossRef]

28. Burton, W.K.; Cabrera, N. Frank, F.C. The growth of crystals and the equilibrium structure of their surfaces. Phil. Trans. R. Soc. A 1951, 243, 299-358. [CrossRef]

29. Bennema, P. Analysis of crystal growth models for slightly supersaturated solutions. J. Cryst. Growth 1967, 1, 278-286. [CrossRef]

30. Bennema, P. The importance of surface diffusion for crystal growth from solution. J. Cryst. Growth 1969, 5, 29-43. [CrossRef]

31. Li, W.; Wang, S.; Ding, J.; Yu, G.; Wang, D.; Huang, P.; Liu, H.; Gu, Q.; Xu, X. Study on micro morphology of potassium dihydrogen phosphate crystals grown at elevated temperatures. Crystals 2017, 7, 118. [CrossRef]

32. Mohan, R.; Myerson, A.S. Growth kinetics: A thermodynamic approach. Chem. Eng. Sci. 2002, 57, 4277-4285. [CrossRef]

33. Li, L.; Rodriguez-Hornedo, N. Growth kinetics and mechanism of glycine crystals. J. Cryst. Growth 1992, 121, 33-38. [CrossRef]

34. Manuel Garcia-Ruiz, J. Nucleation of protein crystals. J. Struct. Biol. 2003, 142, 22-31. [CrossRef] 
35. Mitchell, N.A.; Frawley, P.J. Nucleation kinetics of paracetamol-ethanol solutions from metastable zone widths. J. Cryst. Growth 2010, 312, 2740-2746. [CrossRef]

36. Shiau, L.D. The distribution of dislocation activities among crystals in sucrose crystallization. Chem. Eng. Sci. 2003, 58, 5299-5304. [CrossRef]

37. Park, K.; Evans, J.M.B.; Myerson, A.S. Determination of solubility of polymorphs using differential scanning calorimetry. Cryst. Growth Des. 2003, 3, 991-995. [CrossRef]

38. Murli, C.; Thomas, S.; Venkateswaran, S.; Sharma, S.M. Raman spectroscopic investigation of $\alpha$-glycine at different temperatures. Phys. B 2005, 364, 233-238. [CrossRef]

39. Bouchard, A.; Hofland, G.W.; Witkamp, G.J. Solubility of glycine polymorphs and recrystallization of ß-glycine. J. Chem. Eng. Data 2007, 52, 1626-1629. [CrossRef]

40. Shiau, L.D. The temperature dependence of the pre-exponential factor and interfacial energy for aqueous glycine solutions based on the metastable zone width data. J. Cryst. Growth 2018, 496, 18-23. [CrossRef]

41. Mersmann, A.; Bartosch, K. How to predict the metastable zone width. J. Cryst. Growth 1998, 183, $240-250$. [CrossRef]

(C) 2018 by the author. Licensee MDPI, Basel, Switzerland. This article is an open access article distributed under the terms and conditions of the Creative Commons Attribution (CC BY) license (http:/ / creativecommons.org/licenses/by/4.0/). 